\title{
Current Trends in Etiological Profile of Acute Upper Gastrointestinal Bleeding in Northern India: A Retrospective Analysis of 5-Year Endoscopic Data
}

\author{
Vishal Bodh ${ }^{1}$ Brij Sharma ${ }^{1}$ Rajesh Kumar ${ }^{1}$ Rajesh Sharma ${ }^{1}$ \\ ${ }^{1}$ Department of Gastroenterology, IGMC, Shimla, Himachal \\ Pradesh, India \\ J Digest Endosc 2021;12:31-35. \\ Address for correspondence Rajesh Sharma, MD (Medicine), \\ DNB (Gastroenterology), Department of Gastroenterology, IGMC, \\ Shimla, HimachalPradesh 171001, India \\ (e-mail: rdrsharma@gmail.com).
}

\begin{abstract}
Keywords

- acute upper gastrointestinal bleeding

- esophagogastroduodenoscopy

- portal hypertension

- peptic ulcer disease

Introduction The etiological spectrum of acute upper gastrointestinal bleeding (AUGIB) varies from region to region. This study was performed to find out the latest etiological spectrum of the AUGIB in a tertiary care hospital in North India and to compare it with etiological spectra from a previous study from the same center and from the other regions of India.

Methods Clinical notes and endoscopic data of all consecutive patients who had presented with AUGIB in Indira Gandhi Medical College Shimla, Himachal Pradesh, from May 2015 to December 2019, were analyzed retrospectively with the objective of finding out the various endoscopic etiologies that lead to AUGIB. The findings were compared with the previous study from the same center and with the data from the other regions of the country.

Results A total of 1,513 patients were enrolled and majority were males (74.6\%) with male:female ratio of 2.9:1. Majority were 41 to 60 years (46.46\%) of age. Melena was the presenting complaint in $93.98 \%$ and hematemesis in $46.06 \%$. Peptic ulcer disease (PUD; 46.19\%) was the commonest cause of AUGIB followed by portal hypertension (26.23\%). Other less common causes were erosive mucosal disease, erosive esophagitis, neoplasm, Mallory-Weiss tear, gastric angiodysplasia, anastomotic site ulcers, and Dieulafoy's lesion.

Conclusion PUD was still the commonest cause of AUGIB followed by portal hypertension. This is in agreement with the previous report from the same center and in contrast to the reports from other studies from Northern and Western India that create the impression that portal hypertension related bleeding is the most common cause of AUGIB in India.
\end{abstract}

\section{Introduction}

Acute upper gastrointestinal bleeding (AUGIB), presenting with symptoms of hematemesis, melena, and/or hematochezia, is an important medical emergency. AUGIB is defined

published online January 25, 2021
DOI https://doi.org/

$10.1055 / \mathrm{s}-0041-1728232$ ISSN 0976-5042 as bleeding derived from a source proximal to the ligament of Treitz and is associated with significant morbidity and mortality. ${ }^{1}$ AUGIB presents with a wide range of clinical severity, ranging from insignificant bleeds to catastrophic hemorrhage. $^{2}$ The incidence of upper gastrointestinal

(c)2021. Society of Gastrointestinal Endoscopy of India.

This is an open access article published by Thieme under the terms of the Creative Commons Attribution-NonDerivative-NonCommercial-License, permitting copying and reproduction so long as the original work is given appropriate credit. Contents may not be used for commercial purposes, or adapted, remixed, transformed or built upon. (https://creativecommons.org/licenses/by-nc-nd/4.0/). Thieme Medical and Scientific Publishers Pvt. Ltd. A-12, 2nd Floor, Sector 2, Noida-201301 UP, India 
bleeding (UGIB) ranges from 50 to $150 / 100,000$ population annually, and time trend analyses suggest that it is more common in elderly people. ${ }^{3}$ Patients can be divided as having either variceal or nonvariceal sources of UGIB as the two have different management protocols and prognoses. ${ }^{4}$ The variceal source includes lesions that arise by virtue of portal hypertension, namely, gastroesophageal varices and portal hypertensive gastropathy; and the nonvariceal includes lesions seen in the general population (peptic ulcer, erosive gastritis, reflux esophagitis, Mallory-Weiss syndrome, tumors, etc.).

The etiological spectrum of UGIB varies from region to region. ${ }^{5}$ Population-based epidemiological data revealing the current trends in India are sparse. Globally, the prevalence of Helicobacter pylori infection has decreased due to better hygiene, early diagnosis, and eradication. ${ }^{6}$ These factors have contributed to the changing trends in UGIB. Once frequent, UGIB due to peptic ulcer has now declined all over the globe as demonstrated by various researchers. ${ }^{7,8}$

The primary diagnostic test for evaluation of UGIB is endoscopy. Endoscopy for UGIB has a sensitivity of 92 to $98 \%$ and specificity of 30 to $100 \%{ }^{9}$

At present, there are limited data on endoscopic etiological profile of patients of UGIB from India and particularly from this region. Therefore, this study was performed to find out the current etiological spectrum of the UGIB in the state of Himachal Pradesh in North India and to compare it with previous study from the same center to know the change in etiological profile. This etiological spectrum was also compared with the reported etiological spectrum from the other regions of India to know the current status in the country.

\section{Methods}

In this study we did a retrospective review of the clinical and endoscopic notes of the patients above 1 year of age who presented with AUGIB and underwent diagnostic and therapeutic esophagogastroduodenoscopy (EGD) in the Department of Gastroenterology, Indira Gandhi Medical College (IGMC) and Hospital, Shimla. All patients who had presented with AUGIB in the form of hematemesis, melena, and hematochezia with hemodynamic instability from May 2015 to December 2019 and underwent EGD in the Department of Gastroenterology, IGMC, Shimla, were enrolled in the study. EGD was done by senior gastroenterologist using Olympus EXERA II GIF-H180 Gastroscope after initial hemodynamic stabilization within 72 hours (preferably within the first 24 hours) of bleed to determine the etiology and perform the endoscopic therapy. During endoscopy, band ligation was done for bleeding large esophageal varices, and $N$-butyl cyanoacrylate glue was injected in bleeding gastric varices. For bleeding peptic ulcer, diluted adrenaline was injected around the ulcer base and argon plasma coagulation of the bleeding lesion was performed.

The data analyzed included age, gender, presenting complaint (hematemesis, melena, hematochezia), and endoscopic findings. The objective of the study was to find out the various endoscopic etiologies that lead to AUGIB. Results are displayed in tables and figures, with the categorical variables presented as numbers and percentages. The results of the present study were compared with the previous study by Kashyap et al from the same center to find out any change in the endoscopic etiological profile of the UGIB. ${ }^{10}$ Also, an extensive search from different journals and publications was done to analyze the causes of UGIB in different regions of India. Comparison was made between the present study and other studies on UGIB, to evaluate the current etiological and clinical spectrum of bleeding in different regions of India.

\section{Results}

A total of 1,513 patients had presented with AUGIB and had underwent EGD from May 2015 to December 2019, in Department of Gastroenterology, IGMC, Shimla. The majority of the patients were male (74.6\%), and the male:female ratio was 2.9:1 (- Table 1). Most of the patients were in age group of 41 to 60 years (46.5\%) followed by 61 to 80 years (25.8\%), 21 to 40 years (22.3\%), more than 80 years (2.8\%), and 1 to 20 years (2.6\%; - Table $\mathbf{1})$.

Melena was the presenting complaint in $94.0 \%(1,422)$ $1,513)$ and hematemesis was present in $46.1 \%(697 / 1,513)$. Both hematemesis and melena were seen in $43.0 \%$ (651/ 1,513; - Table 1).

The commonest cause of UGIB was peptic ulcer disease (PUD), accounting for $46.2 \%$ cases. Among the 699 PUD patients, majority had duodenal ulcer ( $n=532 / 699,76.1 \%$ ) followed by gastric ulcer ( $n=105 / 699,15 \%$ ) and simultaneous duodenal and gastric ulcer ( $n=62 / 699,8.9 \%$ ). Among the 699 patients presented with peptic ulcer bleed, majority had Forrest Class III ulcer ( $n=582 / 699,83.3 \%)$ followed by Forrest IIc ( $n=46 / 699,6.6 \%)$, Forrest IIb $(n=31 / 699,4.4 \%)$, Forrest Ib ( $n=18 / 699,2.6 \%)$, and Forrest IIa ( $n=15 / 699,2.1 \%)$. Seven patients (1\%) had Forrest Ia ulcers with active spurting bleed

\section{(-Table 2).}

Portal hypertension related bleeding, including esophageal varices, gastric varices, and portal hypertensive gastropathy, was responsible for bleed in $26.2 \%$. Among the

Table 1 Epidemiological features, clinical presentation, and endoscopic diagnosis of the patients presenting with acute upper gastrointestinal bleeding

\begin{tabular}{|l|l|l|}
\hline & $\begin{array}{l}\text { Number of } \\
\text { patients } \\
(n=1,513)\end{array}$ & Percentage (\%) \\
\hline Males & 1,129 & 74.6 \\
\hline Females & 384 & 25.4 \\
\hline $1-20 y$ & 40 & 2.6 \\
\hline $21-40 y$ & 337 & 22.3 \\
\hline $41-60 y$ & 703 & 46.5 \\
\hline $61-80 y$ & 391 & 25.8 \\
\hline$>80 y$ & 42 & 2.8 \\
\hline Melena & 1,422 & 94.0 \\
\hline Hematemesis & 697 & 46.1 \\
\hline $\begin{array}{l}\text { Hematemesis and } \\
\text { melena }\end{array}$ & 651 & 43.0 \\
\hline
\end{tabular}


397 patients with portal hypertension related bleed, majority had esophageal variceal bleed $(n=356 / 397,89.7 \%)$ followed by gastric variceal bleed $(n=37 / 397,9.3 \%)$ and portal hypertensive related bleed ( $n=4 / 389,1.0 \%$; - Table 2 ). Neoplasms comprised $3.3 \%$ of the total cases, of which carcinoma stomach was most common (3\%) followed by esophageal $(0.2 \%)$ and periampullary $(0.1 \%)$ malignancy. Other less common causes were erosive mucosal disease (6.0\%), gastroesophageal reflux disease with erosive esophagitis (4.2\%), Mallory-Weiss tear (2.8\%), gastric angiodysplasia (0.2\%), anastomotic site ulcers in previous gastric surgery patients $(0.2 \%)$, and Dieulafoy's lesion (0.1\%). In $10.8 \%$ of the patients, no obvious cause could be found on EGD ( - Table 2). These were labeled as having obscure bleed and were subjected to further investigations.

Table 2 Endoscopic finding/diagnosis of the patients presenting with acute upper gastrointestinal bleeding

\begin{tabular}{|c|c|c|}
\hline & $\begin{array}{l}\text { Number of } \\
\text { patients } \\
(n=1,513)\end{array}$ & Percentage (\%) \\
\hline Peptic ulcer disease & 699 & 46.2 \\
\hline A-duodenal ulcer & 532 & 35.2 \\
\hline B-gastric ulcer & 105 & 6.9 \\
\hline $\begin{array}{l}\text { C-both gastric and } \\
\text { duodenal ulcer }\end{array}$ & 62 & 4.1 \\
\hline Forrest I A & 7 & 0.5 \\
\hline Forrest I B & 18 & 1.2 \\
\hline Forrest II A & 15 & 1.0 \\
\hline Forrest II B & 31 & 2.0 \\
\hline Forrest II C & 46 & 3.0 \\
\hline Forrest III & 582 & 38.5 \\
\hline Portal hypertension & 397 & 26.2 \\
\hline $\begin{array}{l}\text { Esophageal variceal } \\
\text { bleed }\end{array}$ & 356 & 23.5 \\
\hline Gastric variceal bleed & 37 & 2.4 \\
\hline $\begin{array}{l}\text { Portal hypertensive } \\
\text { gastropathy }\end{array}$ & 4 & 0.3 \\
\hline $\begin{array}{l}\text { Erosive mucosal } \\
\text { disease }\end{array}$ & 91 & 6.0 \\
\hline $\begin{array}{l}\text { Reflux erosive } \\
\text { esophagitis }\end{array}$ & 63 & 4.2 \\
\hline Gastric malignancy & 45 & 3.0 \\
\hline Mallory-Weiss tear & 42 & 2.8 \\
\hline $\begin{array}{l}\text { Gastric } \\
\text { angiodysplasia }\end{array}$ & 3 & 0.2 \\
\hline $\begin{array}{l}\text { Anastomotic ulcers } \\
\text { in previous gastric } \\
\text { surgery patients }\end{array}$ & 3 & 0.2 \\
\hline $\begin{array}{l}\text { Esophageal } \\
\text { malignancy }\end{array}$ & 3 & 0.2 \\
\hline $\begin{array}{l}\text { Periampullary } \\
\text { malignancy }\end{array}$ & 2 & 0.1 \\
\hline Dieulafoy's lesion & 1 & 0.1 \\
\hline Obscure & 164 & 10.8 \\
\hline
\end{tabular}

\section{Discussion}

UGIB is a common medical emergency seen in tertiary care centers. The etiology of UGIB may vary in different geographical regions. In this study, we retrospectively analyzed the endoscopic data of 1,513 patients from Northern India who presented with acute UGIB.

The present study shows that the PUD is the commonest cause of UGIB in the state of Himachal Pradesh in Northern India followed by portal hypertension related bleed. This is in agreement with the previous study by Kashyap et al from the same center. ${ }^{10}$ Though the percentage of the patients with PUD has decreased (from $61 \%$ in previous study to $46.2 \%$ in present study) and percentage of the patients with portal hypertension related bleed has increased (from $10.8 \%$ in previous study to $26.2 \%$ in the present study) compared with the previous study, still the PUD is the leading cause followed by portal hypertension related bleed ( - Table 3 ).

- Table 3 shows comparison of the patient profile and endoscopic etiologic spectrum of the UGIB from different parts of India. ${ }^{11-17}$ Though to a variable degree, but male preponderance was seen in all the studies on UGIB from different regions of India (Table 3). ${ }^{11-15,18,19}$ Most of the patients presenting with UGIB in present study were in age group of 41 to 60 years (46.5\%). Similar findings have been reported by Parvez et al from Eastern India where majority (54\%) of the patients were in the age group of 20 to 60 years. Prasad et al from South India reported that majority of patients (52.3\%) presenting with acute UGIB were also in the age group of 41 to 60 years. ${ }^{16}$ But western studies report a higher age at presentation, which is due to elderly population in their community. ${ }^{17,20}$

Melena was the most common presentation in our study (95.1\%) followed by hematemesis (46.1\%) and combined hematemesis and melena (43.0\%). Similar findings are seen in a study by Singh and Panigrahi where melena was the presenting complaint in $95.1 \%$, hematemesis was present in $43.1 \%$, and both hematemesis and melena were seen in $41.8 \%$ (- Table 4). ${ }^{14}$ In contrast, the study by Parvez et al from eastern India revealed that hematemesis was the more common presentation (60.8\%). ${ }^{12}$ In an another study by

Table 3 Comparison of the endoscopic etiological spectrum of the present study with the previous study from the same center

\begin{tabular}{|l|l|l|}
\hline $\begin{array}{l}\text { Endoscopic } \\
\text { diagnoses }\end{array}$ & $\begin{array}{l}\text { Percentage of } \\
\text { patients: present } \\
\text { study (2020) } \\
\text { from Shimla }\end{array}$ & $\begin{array}{l}\text { Percentage of } \\
\text { patients: previous } \\
\text { study (2005) } \\
\text { from Shimla 19 }\end{array}$ \\
\hline $\begin{array}{l}\text { Peptic ulcer disease } \\
\text { (duodenal ulcer + } \\
\text { gastric ulcer) }\end{array}$ & 46.2 & 61.0 \\
\hline Portal hypertension & 26.2 & 10.8 \\
\hline $\begin{array}{l}\text { Erosive mucosal } \\
\text { disease }\end{array}$ & 6.0 & 11.7 \\
\hline Mallory-Weiss tear & 2.8 & 10.8 \\
\hline Reflux esophagitis & 4.2 & 2.7 \\
\hline Tumors & 3.3 & 3.6 \\
\hline
\end{tabular}


Table 4 Comparison of clinical and etiological spectrum of upper gastrointestinal bleeding in different regions of India

\begin{tabular}{|c|c|c|c|c|c|c|c|c|}
\hline & $\begin{array}{l}\text { Present } \\
\text { Study }\end{array}$ & Delhi' ${ }^{18}$ & Mumbai ${ }^{19}$ & Chennai ${ }^{11}$ & Kolkata $^{12}$ & Kerala $^{13}$ & Odisha $^{14}$ & $J^{a m m u^{15}}$ \\
\hline Year of study & 2020 & 1983 & 2001 & 2015 & 2016 & 2009 & 2012 & 2015-2017 \\
\hline Study population & 1,513 & 408 & 398 & 408 & 337 & 1,582 & 608 & 1,270 \\
\hline Male:female ratio & $2.9: 1$ & $3: 1$ & $3.5: 1$ & $2.2: 1$ & $4: 1$ & NA & $3.6: 1$ & 1.6:1 \\
\hline Melena (\%) & 94.0 & NA & NA & NA & 50.7 & NA & 95.1 & 10.9 \\
\hline Hematemesis (\%) & 46.1 & NA & NA & NA & 60.8 & NA & 43.1 & 20.9 \\
\hline $\begin{array}{l}\text { Hematemesis + } \\
\text { melena (\%) }\end{array}$ & 43.0 & NA & NA & NA & NA & NA & 41.8 & 67.8 \\
\hline $\begin{array}{l}\text { Peptic ulcer dis- } \\
\text { ease (duodenal + } \\
\text { gastric ulcer) (\%) }\end{array}$ & 46.2 & 30 & 15.3 & 17.8 & 40.2 & 35 & 58.7 & 18.3 \\
\hline $\begin{array}{l}\text { Portal hyperten- } \\
\text { sion bleed (\%) }\end{array}$ & 26.2 & 45.5 & 56 & 33.3 & 33.8 & 30.9 & 12.8 & 43.5 \\
\hline $\begin{array}{l}\text { Erosive mucosal } \\
\text { disease (\%) }\end{array}$ & 6.0 & 8.5 & 4.5 & 43.6 & 10.6 & 13 & 1.2 & 16.2 \\
\hline Malignancy (\%) & 3.3 & NA & 0.75 & 2.4 & 2.9 & 2 & 7.9 & 2.4 \\
\hline
\end{tabular}

Mahajan and Chandail from Jammu among patients aged 40 years or more, presentation with combined hematemesis and melena (68.1\%) was more common. ${ }^{15}$

When nonvariceal bleeding versus variceal is considered as the etiology of UGIB, there are variable results in India. In the present study, PUD (46.2\%) was the predominant etiology followed by the portal hypertensive bleed $(26.2 \%$; - Table 3). Similar findings reporting duodenal ulcer being the most common cause of UGIB followed by variceal bleed have been reported by Parvez et al ${ }^{12}$ from Kolkata and Singh and Panigrahi ${ }^{14}$ from Odisha (- Table 4). This is in contrast to the spectra reported by Anand et $\mathrm{al}^{18}$ from Delhi, Rathi et $\mathrm{al}^{19}$ from Mumbai, and Mahajan and Chandail ${ }^{15}$ from Jammu, of Northern and Western India, that create the impression that variceal bleeding is the most common cause of UGIB in India

\section{(-Table 4).}

In developing countries, like India, there is gross disparity in health care access, with advanced health care technologies and well-trained health care specialists being concentrated among the urban minority. ${ }^{21}$ Endoscopy services are unavailable in almost all public primary and secondary care centers in India. ${ }^{21}$ Peptic ulcer related bleeds are likely to more often cease spontaneously and rebleed less frequently vis-a-vis variceal bleeds.2. The distance to the nearest available endoscopy service might be a confounding factor when looking for epidemiological differences in the etiology of UGIB in India. This difference has been reported by $\mathrm{Das}^{23}$ in his retrospective audit of etiology of UGIB in a district center (DC), providing diagnostic UGIB services every weekend, vis-a-vis a tertiary care academic center (TC), in West Bengal, eastern India. There were significant differences between the etiologies of UGIB in the two centers. PUD was more frequent in the DC, while varices were more frequent in the TC as the cause of AUGIB. Similarly, another recent study from a tertiary care center of same region in eastern India by Banerjee et $\mathrm{al}^{24}$ also reported portal hypertension (62.30\%) as the most common etiology of UGIB followed by PUD (16.70\%). So, the studies done from the tertiary care centers of eastern India revealed the portal hypertension related bleed to be the most common of AUGIB, while the study performed in the DC of the same region showed the PUD-related bleed as the most common etiology of AUGIB. This clearly reflects the disparity in the access to health care. PUD as the most common etiology of AUGIB is seen in the present study, similar to the findings seen by Das $^{23}$ in DC, as our center is also a peripheral tertiary health care center, situated in the hilly state of Himachal Pradesh.

So, the variable spectrum of the etiology of the AUGIB seen in our country could represent either a true epidemiological difference or reflect skewed access to health care. It seems likely that the studies conducted in the major referral centers of India may represent the referral bias in the etiological spectrum of AUGIB, as critical patients with variceal bleed requiring endoscopic and surgical intervention from all over the region were referred to these hospitals, which may have added on to the percentage of patients with variceal bleed. These figures are thus not representative of the actual etiological spectrum of AUGIB in this country.

\section{Conclusion}

PUD-related bleed is still the commonest cause of UGIB in the state of Himachal Pradesh in North India followed by portal hypertension related bleed. This is in agreement with the previous report from the same center suggesting a similar trend for the etiological spectrum of the UGIB in this region and in contrast to other studies from North and West India that create the impression that portal hypertension related variceal bleeding is the most common cause of UGIB in India. 


\section{Source(s) of Support \\ None.}

\section{Conflict of Interest}

None.

\section{References}

1 Ghosh S, Watts D, Kinnear M. Management of gastrointestinal haemorrhage. Postgrad Med J 2002;78(915):4-14

2 Rockall TA, Logan RF, Devlin HB., Northfield TC; National Audit of Acute Upper Gastrointestinal Haemorrhage. Selection of patients for early discharge or outpatient care after acute upper gastrointestinal haemorrhage. Lancet 1996;347(9009): $1138-1140$

3 Thomopoulos KC, Vagenas KA, Vagianos CE, et al. Changes in aetiology and clinical outcome of acute upper gastrointestinal bleeding during the last 15 years. Eur J Gastroenterol Hepatol 2004;16(2):177-182

4 Ginn JL, Ducharme J. Recurrent bleeding in acute upper gastrointestinal hemorrhage: transfusion confusion. CJEM 2001; 3(3):193-198

5 van Leerdam ME. Epidemiology of acute upper gastrointestinal bleeding. Best Pract Res Clin Gastroenterol 2008;22(2): 209-224

6 Frugis S, Czeczko NG, Malafaia O, et al. Prevalence of Helicobacter pylori ten years ago compared to the current prevalence in patients undergoing upper endoscopy. Arq Bras Cir Dig 2016;29(3):151-154

7 Jiang M, Chen P, Gao Q. Systematic review and net-work meta-analysis of upper gastrointestinal hemorrhage interventions. Cell Physiol Biochem 2016;39(6):2477-2491

8 Roberts-Thomson IC. Rise and fall of peptic ulceration: a disease of civilization? J Gastroenterol Hepatol 2018;33(7):1321-1326

9 Jaskolka JD, Binkhamis S, Prabhudesai V, Chawla TP. Acute gastrointestinal hemorrhage: radiologic diagnosis and management. Can Assoc Radiol J 2013;64(2):90-100

10 Kashyap R, Mahajan S, Sharma B, et al. A clinical profile of acute upper gastrointestinal bleeding at moderate altitude. JIACM 2005;6:224-228

11 Krishnakumar R, Padmanabhan P, Premkumar, Selvi, C, Ramkumar, Joe, A. Upper GI bleed- a study of 408 cases. Indian J Gastroenterol 2007;26(suppl 2):A133

12 Parvez M, Goenka MK, Tiwari IK, Goenka U. Spectrum of upper gastrointestinal bleed: an experience from eastern India. J Dig Endosc 2016;7:55-61
13 Gajendra O, Ponsek T, Varghese J, Sadasivan S, Nair P, Narayanan VA. Single center study of upper GI endoscopic findings in patients with overt and occult upper GI bleed. Indian J Gastroenterol 2009;28:A111

14 Singh SP, Panigrahi MK. Spectrum of upper gastrointestinal hemorrhage in coastal Odisha. Trop Gastroenterol 2013;34(1): 14-17

15 Mahajan P, Chandail VS. Etiological and endoscopic profile of middle aged and elderly patients with upper gastrointestinal bleeding in a tertiary care hospital in North India: a retrospective analysis. J Midlife Health 2017;8(3):137-141

16 Prasad NRV, Ali SM, Ganapathy V, Sreenath GS, Kumar SS. Acute upper gastrointestinal bleeding in a tertiary care hospital in South India - have we improved the outcomes? Trop Gastroenterol 2016;37(3):168-176

17 Marmo R, Koch M, Cipolletta L, et al; Italian registry on upper gastrointestinal bleeding (Progetto Nazionale Emorragie Digestive-PNED 2). Predicting mortality in non-variceal upper gastrointestinal bleeders: validation of the Italian PNED Score and prospective comparison with the Rockall Score. Am J Gastroenterol 2010;105(6):1284-1291

18 Anand CS, Tandon BN, Nundy S. The causes, management and outcome of upper gastrointestinal haemorrhage in an Indian hospital. Br J Surg 1983;70(4):209-211

19 Rathi P, Abraham P, Jakareddy, R, Pai, N. Spectrum of upper gastrointestinal bleeding in western India. Indian J Gastroenterol 2001;20(suppl 2):A37

20 Romagnuolo J, Barkun AN, Enns R, Armstrong D, Gregor J. Simple clinical predictors may obviate urgent endoscopy in selected patients with nonvariceal upper gastrointestinal tract bleeding. Arch Intern Med 2007;167(3):265-270

21 Report of the National Commission on Macroeconomics and Health. Ministry of Health and Family Welfare. Government of India, New Delhi, 2005

22 Wara P. Incidence, diagnosis, and natural course of upper gastrointestinal hemorrhage. Prognostic value of clinical factors and endoscopy. Scand J Gastroenterol Suppl 1987;137:26-27

23 Das K. Endoscopy outreach and upper gastrointestinal bleed: an audit. Indian J Gastroenterol 2014;33(5):478-479

24 Banerjee A, Bishnu S, Dhali GK. Acute upper gastrointestinal bleed: an audit of the causes and outcomes from a tertiary care center in eastern India. Indian J Gastroenterol 2019; 38(3):190-202 